\title{
Serum Taurine Level in Relation to Ophthalmoscopic Examination as Early Marker for Diabetic Retinopathy Ibrahim M El Agouza ${ }^{1}$, Ali H Saad ${ }^{2}$, Amr A Mahfouz $^{3}$ and Kholod Hamdy ${ }^{1 *}$ \\ ${ }^{1}$ Zoology Department, Faculty of Science, Cairo University, Cairo, Egypt \\ ${ }^{2}$ Ophthalmology Department, Faculty of Medicine, Ain shams University, Cairo, Egypt \\ ${ }^{3}$ Department of Endocrinology, National Institute of Diabetes and Endocrinology, Cairo, Egypt
}

*Corresponding author: Kholod Hamdy, Zoology Department, Faculty of Science, Cairo University, Cairo, Egypt, Tel: 01128455876; E-mail: kholodt90@gmail.com

Received date: February 04, 2017; Accepted date: April 03, 2017; Published date: April 06, 2017

Copyright: (c) 2017 Agouza IME, et al. This is an open-access article distributed under the terms of the Creative Commons Attribution License, which permits unrestricted use, distribution, and reproduction in any medium, provided the original author and source are credited.

\begin{abstract}
Aim: Investigate the possibility of using serum taurine level in addition to ophthalmoscopic examination as early marker for diagnosis diabetic retinopathy.

Patients and methods: eighty diabetic patients presented with blurring in vision were chosen from the National Institute of Diabetes and Endocrinology after their approval. Twenty healthy volunteers were enrolled as frank control. According to the image of ophthalmoscopic examination, patients were classified into four grades (mild, moderate, sever non-proliferative and proliferative) of retinopathy. Complete clinical examination, investigation and biochemical analysis, measuring FBG, HbA1c, VEGF and taurine were measured for all included subjects.

Results: Non-significance change in LDL and triglycerides for all stages with respect to control group. HDL and cholesterol showed significant with frank group. Albumin and creatinine for some stages of retinopathy showed nonsignificance changes with respect to control group. Urea recorded significant in all grades when comparing with control group, all included patients showed either micro or macroalbuminurea. AST and ALT showed highly significant in late stage comparing with frank group. Serum VEGF significant for all stages with frank group. Highly significant elevation in FBG and serum $\mathrm{HbA} 1 \mathrm{c}$ was found parallel to the severity of disease. Compared to healthy group, a highly significant decrease in the level of serum taurine was recorded in all patients. Such decrease was correlated the grading of retinopathy ranting from mild non-proliferative to proliferative.
\end{abstract}

Conclusion: We advise measuring serum taurine level and ophthalmoscopic examination regularly for all persons with diabetes as a pre early marker for diabetic retinopathy.

Keywords: Taurine; Diabetes; Retinopathy; Ophthalmoscope; VEGF; Nephropathy

Abbreviations: FBG: Fasting blood glucose; HbA1c: Glaciated haemoglobin; VEGF: Vascular endothelial growth factor; AST: Aspertat transmenase; ALT: Alanin transmenase; HDL: High density lipoprotine; LDL: Low density lipoprotine.

\section{Introduction}

Diabetes mellitus is recognized as a being syndrome, a collection of disorders that have hyperglycemia and glucose intolerance as their hallmark; due either to insulin deficiency or to impaired effectiveness of insulin action or combination of both. The major types of diabetes are type 1 (insulin depend on diabetes mellitus), type 2 (non-insulin depend on diabetes mellitus) and other categories as genetic defect of B-Cell function, genetic defect on insulin action, endocrinopathes and gestational diabetes [1]. The impact of type 2 diabetes mellitus (T2DM) is increasingly felt around the world, with its prevalence rising dramatically over recent decades. There will be a $42 \%$ and $170 \%$ increase in developed and developing countries respectively. In 2013 , 382 million adults were diagnosed with diabetes worldwide with these number is expected to reach 592 million in 2035 [2].
Diabetes is prevalent in All Arabs countries despite the difference in economic status among these countries. Thus genetic susceptibility, culture factors, obesity and practicing less exercise may play an important role in development of the disease. The majority of type 2 diabetes occur in over Weight and obese children with two to six times higher prevalence in girls. They have clinical signs of insulin resistance, such as acanthosis nigricans. The mean age of onset is around puberty in most population. Currently, the mainstay of differentiating diabetes in children is inadequate and include the use of clinical characteristics such as severity of onset, use of insulin, age of onset, diabetic ketoacidosis and family history of diabetes [2].

Egypt is among the world top 10 countries in the number of persons with diabetes [3]. Were diabetes contentious to be public health problem with significant burden on Egyptian economy. The prevalence of diabetes is around $15.5 \%$ among adult of age ranging between $20-79$ years [4]. It is worthy to mention that diabetes prevalence in Egypt has dramatically increased within a relatively short period. From 2007 to 2013 the number of patients with diabetes increases from 4.4 million to 7.5 million [3]. Such alarming increase may be attributed to bad life style, unhealthy eating habits and sedentary life style of Egyptian youth [4]. 
The development of chronic vascular complications is common in type 1 and type 2 of diabetes mellitus. In general, they are divided into micro- and macrovascular complications. The most prevalent microvascular complications are retinopathy, nephropathy and neuropathy [5], whereas cardiac, peripheral arterial and cerebrovascular diseases are the most common macro vascular complications associated with diabetes [6].

The epidemiologic studies demonstrated that those with diabetes are more likely to develop cancer. The mechanisms through which this may occur are incompletely understood [7]. In 2010, it was reported that the aim of examining the knowledge regarding the association between diabetes and cancer, exploring the risk factors for both conditions, to examine their possible biologic links and to determine whether certain treatments for diabetes modify cancer risk [8].

Retinopathy Is a clinically well defined, specific microvascular complication of diabetes. It is the most common ocular complication that leads to visual loose among adults at working age in the developed world [9]. The clinical signs of diabetic retinopathy include microaneeuroysm, haemorrhage, intraretinal microvascular abnormalities and neovascularization [10]. Microaneuroysms are first clinically sign of diabetic retinopathy, they represent weakening of the capillary walls. Haemorrhage are damage of blood vessel. It can occur deeper in retina and follow the retinal nerve fiber layer. Intraretinal microvascular abnormalities caused by poor functional or nonperfusion of capillaries which prevent normal blood flow. Neovascularization can occur with retina as a response to ischemia and it is mark of late stage of retinopathy. The presented of neovascularization increase the risk of vision loose in patient with diabetes [11]. Despite advances in the management of diabetic retinopathy, macular edema remain the leading cause of blindness in the diabetic population. Macular edema effect up to $14 \%$ of all diabetic patients [12]. Ophthalmoscopic examination playing important roles in the screening, monitoring of the diabetic retinopathy and is a more accurate and objective method for diagnosis of these disease. It offers high resolution, three-dimensional or cross-sectional images that closely approximate the histological appearance of the retina [13]. According to ophthalmoscopic image, retinopathy could be classified in to non-proliferative and proliferative retinopathy. Non-proliferative retinopathy is further subdivided into mild, moderate and sever. This classification aim to identify stages of retinopathy that may present a significant threat to visual acuity or confer high risk for progression to those stages, which in turn guides follow up duration and necessity for intervention [10]. Vascular endothelial growth factor (VEGF), Is an angiogenic factor with endothelial cell-selective mitogenic activity, is a key mediator in the retinal vasculature changes involved in the development and progression of diabetic retinopathy [14-16].

In diabetic retinopathy, VEGF play a role in the neovascularization of proliferative retinopathy and in the breakdown of the blood retinal barrier that is characterized by hyperpermiability of retinal vessels [17]. Also, its levels have been found to be markedly elevated in the vitreous and aqueous fluids of patients with proliferative diabetic retinopathy [18]. One third of diabetic retinopathy patients include late stages sever or proliferative retinopathy [19]. Prevalence rate of proliferative retinopathy to be $23 \%$ (younger onset group), $10 \%$ (olderonset group on insulin), and 3\% in people not take insulin. Effort are needed including increasing the frequency of examination and screaming for those at risk developing of proliferative diabetic retinopathy [20]. The three major modifiable risk factors, including hyperglycemia, hypertension, and dyslipidemia are play important role in management of diabetic retinopathy, thus reducing glycated hemoglobin levels by $1 \%$ through intensive glycemic control reduced the risk of DR by $15-40 \%$ [21].

Taurine, ( 2 amino ethane sulfonic acid) is widely distributed and is found in millimolar concentration in mammalian tissue. Taurine is essential amino acid produced in the liver which derived from methionin and cystine metabolism. The main source of taurine is from dietary intake of meat or seafood. It has many important and beneficial effect on the human body. Taurine modulates a verity of cellular functions, ion movement, osmoregulation and modulation of neurotransmitter [22]. It play an important role in initiation and progression of immune response [23], More ever it has a protective against hyperglycemia [24], hypertension [25], endothelial dysfunction [26] and neoplasia [27].

Taurine has been implicated in many aspects of retinal homeostasis. It is found in high concentration in the outer retina, rod cell, retinal pigment epithelium and photo receptors [28]. More ever, through modulation of membrane ion channels, taurine increase $\mathrm{Ca}^{++}$up take to promote the transmission of visual signals from retina to the brain and also is important for the regeneration of damaged cells in the retina [29].

\section{Patients and Methods}

Eighty patients having T2DM under medical treatment for diabetes (tablet only) aging from (18-60) years old were recruited in these study. Ten of them not suffered from any diabetic complication and considered as diabetic control group. Patients with severe neuropathy, nephropathy, who had scars in their feet and history of series cerberovascular or cardiovascular disease were excluded from participating in these studies. After fasting for at least 12 hours, venous blood samples were extracted from all patients for estimation of serum triglecrides, cholesterol, HDL, LDL, HbAlc and taurine levels. While, measuring of serum AST, ALT, VEGF, Blood urea, Creatinine, Albumine and microalbumine were not needed fasting period. After full clinical examination the patients were classified in to five groups according the ophthalmoscope staging. Twenty healthy persons were enrolled as a volunteer and considered as a frank control group. The examined groups are;

- Frank control group $(\mathrm{NO}=20)$

- Control diabetic group $(\mathrm{NO}=10)$

- Mild non-proliferative group $(\mathrm{NO}=10)$

- Moderate non-proliferative group $(\mathrm{NO}=10)$

- Sever non-proliferative group $(\mathrm{NO}=20)$

- Proliferative group $(\mathrm{NO}=30)$

HbAlc microcolumn chromatography kits were obtained from Biosystems, Spain. Serum glucose, ALT, AST, total and HDLcholesterol, triglycerides, urea, creatinine, albumin were purchased from Randox laboratories, UK. While VEGF determination kit was purchased from Wkea Med Supplies Corp. Serum taurine was determined by High Performance Liquid Chromagraphy according to the pre-column extraction and derivatization methodology of McMahon et al. in the present work we use the Shimadzu, Japan, HPLC model LC-10AT.

No correlation between gender and either severity or progression of diabetic retinopathy. More ever, it was postulated that sex and age did not seem to affect the prevalence of diabetic retinopathy when adjustments were made for the duration of disease [30]. 


\section{Statistical Analysis}

After confirmation of normal distribution for all variables, the significance of differences was evaluated by paired t-test or analysis of variance (ANOVA). Relationships between variables were analyzed by simple correlation analysis. Data are expressed as mean $\mathrm{SD}$, and a value of $\mathrm{P}<0.05$ was the criterion for statistical significance.

\section{Results}

The study included seventy diabetic patients presented with only blurring in vision beside ten diabetic patients not suffered from any diabetic complications. Twenty healthy persons enrolled as a volunteer Regarding to the data of lipid profile (Table 1) the result revolves that the desirable value of total cholesterol in frank control group less than $200 \mathrm{mg} / \mathrm{dl}$ and the border line value between $200-240 \mathrm{mg} / \mathrm{dl}$ and become risky when it exhibited a value more than $240 \mathrm{mg} / \mathrm{dl}$. So, all the examined diabetic patients showed mild hypercholesterolemia with no significant changes $(\mathrm{P}>0.05)$ between the difference diabetic groups, but significant increase regard to frank control group. The results revealed a non-significant change $(\mathrm{P}>0.05)$ in the level of triglycerides (TG) between the difference diabetic groups or between the diabetic group and frank persons. The high density lipoprotein (HDL) showed highly significant decreased in all diabetic patients whatever controlled or presented with different stages of retinopathy $(\mathrm{P}<0.000)$. Contrary, low density lipoprotein (LDL) showed non-significant changes between all the diabetic patients and frank control. Regarding to liver enzymes (AST, ALT). The lab of the NIDE and according to the method used the level of AST considered as normal below $40 \mathrm{U} / \mathrm{L}$. So, the level of both enzymes showed no significant changes between the diabetic patients and the frank control group.

\begin{tabular}{|c|c|c|c|c|c|}
\hline & Creatinine & Urea (mg/dl) & Albumin (mg/dl) & $\begin{array}{l}\begin{array}{l}\text { Micro-Albumin } \\
\text { urine) }\end{array} \text { (mg/dl) (in } \\
\text { (n) }\end{array}$ & $\begin{array}{l}\text { Albumin/creatinin (mg/dl) } \\
\text { (in urine) }\end{array}$ \\
\hline Normal range & $0.5-1.5$ & $<50$ & $3.5-5.5$ & & \\
\hline Frank & $0.72 \pm 0.09$ & $16.9 \pm 6.9$ & $3.5 \pm 0.12$ & $39.26 \pm 10.26$ & $40.7 \pm 5.5$ \\
\hline $\begin{array}{l}\text { Diabetic control } \\
\mathrm{N}=10\end{array}$ & $0.80 \pm 0.00 \mathrm{~A}$ & $29.5 \pm 10.9 \mathrm{~A}$ & $3.4 \pm 0.28 \mathrm{~A}$ & $28.05 \pm 10.10 \mathrm{~A}$ & $28.8 \pm 7.4 \mathrm{~A}$ \\
\hline Mild $N=10$ & $0.87 \pm 0.23 \mathrm{~A}, \mathrm{~b} n \mathrm{~s}$ & $46.4 \pm 15.8 \mathrm{~A}^{* * *} \mathrm{~b}^{*}$ & $3.8 \pm 0.23 A^{*}, b n s$ & $216.7 \pm 411 \mathrm{~A} \mathrm{~b} \mathrm{~ns}$ & $468 \pm 857 A^{*}, b$ ns \\
\hline Moderate $\mathrm{N}=10$ & $0.83 \pm 0.29 \mathrm{~A}, \mathrm{~b}, \mathrm{c} \mathrm{ns}$ & $32.8 \pm 12.3 \mathrm{~A}^{* *}, \mathrm{~b}, \mathrm{c}^{*}$ & $3.5 \pm 0.43 \mathrm{~A}, \mathrm{~b}, \mathrm{c}^{*}$ & $365.9 \pm 590 A^{*} b c n s$ & $465 \pm 753 A^{*}, b c n s$ \\
\hline Sever $\mathrm{N}=\mathbf{2 0}$ & $1.0 \pm 0.25 A^{* * *} b^{*}, c^{*}, d^{* *}$ & $45.11 \pm 22.1 \mathrm{~A}^{* * *} \mathrm{~b}^{*} \mathrm{c} \mathrm{d}^{*}$ & $\begin{array}{l}3.6 \pm 0.57 \mathrm{~A} \mathrm{~b} \mathrm{c} \mathrm{d} \\
\mathrm{ns}\end{array}$ & $343 \pm 369 A^{*} b c d n s$ & $224 \pm 242 \mathrm{~A}, \mathrm{~b}, \mathrm{c} \mathrm{d}^{*}$ \\
\hline Proliferative $\mathrm{N}=30$ & $0.79 \pm 0.14 \mathrm{~A}, \mathrm{~b}, \mathrm{c}, \mathrm{d}, \mathrm{e}^{*+* *}$ & $32.5 \pm 10.8 \mathrm{~A}^{* * *}, \mathrm{~b}, \mathrm{c}^{* *}, \mathrm{~d}, \mathrm{e}^{* * *}$ & $\begin{array}{l}3.5 \quad \pm \quad 0.29 \\
\mathrm{~A}, \mathrm{~b}, \mathrm{c}^{*}, \mathrm{~d}, \mathrm{e}\end{array}$ & $186.1 \pm 344 \mathrm{Abcdens}$ & $540 \pm 713 A^{* *} b^{*} c d e^{*}$ \\
\hline
\end{tabular}

Table 1: The kidney functions in different groups of patients. Data are expressed as mean $\pm S D$, A: refers to frank group B: refers to Diabetic control group C: refers to Mild group, D: refers to Mod. group E: refers to Server group, P value $>0.05$ Non-significant (ns), ${ }^{*}$ Significant at level $<0.01,{ }^{* *}$ Highly Significant at level $<0.00,{ }^{* * *}$ very highly Significant $<0.000, \mathrm{P}$ value 0.01 to 0.05 Significant ${ }^{*}, \mathrm{P}$ value 0.0001 to 0.01 high significant $^{* *}, \mathrm{P}$ value 0.0001 to 0.001 extremely significant ${ }^{* *}$.

Table 2 showed that serum creatinine in healthy persons ranged between $0.5-1.5 \mathrm{mg} / \mathrm{dl}$, so there are no any pathological changes recorded between frank control group $(0.72+0.09)$ and the diabetic groups, because all of the exhibited values less than $1.5 \mathrm{mg} / \mathrm{dl}$. Same observation recorded in blood urea, our healthy volunteers showed a value $16.9 \pm 6.9 \mathrm{mg} / \mathrm{dl}$ and the diabetic control group increased to 29.5 $\pm 10.9 \mathrm{mg} / \mathrm{dl}$ and reach to $46.4 \pm 15.8 \mathrm{mg} / \mathrm{dl}$ in mild non-proliferative group. In spite of the highly significant $(\mathrm{P}<0.001)$ increases recorded in the other diabetic patients $(32.8 \pm 12.3,45.11 \pm 22.1,32.5 \pm 10.8)$ in moderate, sever non-proliferative and proliferative group respectively. These increments not indicated renal impairment. Serum albumin in frank control group is $3.5 \pm 0.12 \mathrm{mg} / \mathrm{dl}$ and increased non-significant in mild non-proliferative retinopathy to $3.8 \pm 0.23 \mathrm{mg} / \mathrm{dl}$. Same observation was recorded in measuring microalbumin and albumin/ creatinine ratio in urine when the result showed a non-significant change between frank control group and different diabetic groups $(\mathrm{P}>0.05)$. Table 3 illustrated the marked elevation $(\mathrm{P}<0.0001)$ in $\mathrm{FBG}$ in all diabetic patients comparing to that recorded in frank control group. Logically, HbAlc showed highly significant $(\mathrm{P}<0.0001)$ elevation in all diabetic patients to exhibit a value of $101 \mathrm{mmol} / \mathrm{mol}$ in proliferative retinopathy to $35 \mathrm{mmol} / \mathrm{mol}$ in frank control group. Contrary, in controlled diabetic patients slightly increased $(\mathrm{P}>0.05)$ to exhibit a value $48 \mathrm{mmol} / \mathrm{mol}$. Serum VEGF showed mild decrease in all diabetic patients referring to that observed in frank control group. The most interesting point in our result illustrated in Table 3, when serum taurine level was markedly $(\mathrm{P}<0.0001)$ decreased in control diabetic group. These decrements were continuous parallel to the stage of retinopathy from mild to moderate to severe non-proliferative to proliferative stage. 
Citation: Agouza IME, Saad AH, Mahfouz AA, Hamdy K (2017) Serum Taurine Level in Relation to Ophthalmoscopic Examination as Early

Page 4 of 8

\begin{tabular}{|c|c|c|c|c|c|c|}
\hline & $\underset{>40}{\text { AST }} \quad(\mathrm{U} / \mathrm{L})$ & $\underset{>50}{\operatorname{ALT}} \quad(\mathrm{U} / \mathrm{L})$ & $\begin{array}{l}\text { LDL Optimal <100, near } \\
\text { optimal 100-130, bor line } \\
130-160\end{array}$ & 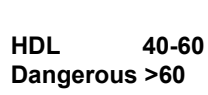 & $\begin{array}{l}\text { Triglycerides }(\mathrm{mg} / \mathrm{dl}) \\
\text { Desirable }<150, \text { board line } \\
150-200 \text { High }>200\end{array}$ & $\begin{array}{l}\text { Cholesterol (mg/dl) Dangerous } \\
<200 \text {, board line 150-200 Risky } \\
>250\end{array}$ \\
\hline \multicolumn{7}{|c|}{ Normal range } \\
\hline Frank $\mathrm{N}=20$ & $19.3 \pm 5.11$ & $16.8 \pm 3.6$ & $129.1 \pm 16.5$ & $64.0 \pm 11.2$ & $144.7 \pm 24.8$ & $178.3 \pm 30.4$ \\
\hline $\begin{array}{l}\text { Diabetic } \\
\text { control } \\
\mathrm{N}=10\end{array}$ & $22.0 \pm 2.3 \mathrm{~A}$ & $22.5 \pm 7.5 \mathrm{~A}$ & $146.5 \pm 82.5 \mathrm{~A}$ & $43.5 \pm 9.8 A^{* * *}$ & $198.5 \pm 98.7 \mathrm{~A}$ & $230 \pm 72.1 \mathrm{~A}$ \\
\hline Mild $N=10$ & $\begin{array}{l}21.7 \pm 3.8 \mathrm{Ab} \\
\mathrm{ns}\end{array}$ & $\begin{array}{l}42.5 \pm 49.8 \\
\mathrm{~A}^{*}, \mathrm{~b} \mathrm{~ns}\end{array}$ & $147.9 \pm 41.9 \mathrm{~A}, \mathrm{~b}$ ns & $\begin{array}{l}43.7 \pm 6.0 A^{* * *} b \\
\text { ns }\end{array}$ & $233.6 \pm 93.0 \mathrm{Abns}$ & $238 \pm 59.3 A^{* *}, b$ ns \\
\hline $\begin{array}{l}\text { Moderate } \\
\mathrm{N}=10\end{array}$ & $\begin{array}{l}32.0 \pm 11.8 \mathrm{~A} \\
\mathrm{bcns}\end{array}$ & $\begin{array}{l}40.8 \pm 23.7 \\
\mathrm{~A}^{*}, \mathrm{~b} \mathrm{c} n \mathrm{~ns}\end{array}$ & $151.2 \pm 56.0 \mathrm{~A}, \mathrm{~b}, \mathrm{c} \mathrm{ns}$ & $\begin{array}{l}43.2 \pm 10.8 A^{\star * *} b \\
\text { c ns }\end{array}$ & $232.5 \pm 90.6 \mathrm{~A} b \mathrm{cns}$ & $241 \pm 65.2 \mathrm{~A}^{* *}, \mathrm{~b} \mathrm{c} \mathrm{ns}$ \\
\hline Sever $N=20$ & $\begin{array}{l}35.5 \pm 22.8 A^{*} \\
\text { b c d ns }\end{array}$ & $\begin{array}{l}32.8 \pm 20.2 \mathrm{~A} \\
\mathrm{bcdns}\end{array}$ & $141.2 \pm 55.8 \mathrm{~A}, \mathrm{~b}, \mathrm{c}, \mathrm{d} \mathrm{ns}$ & $\begin{array}{l}49.2 \pm 12.2 A^{* * *} b \\
c d n s\end{array}$ & $141.6 \pm 70.7 \mathrm{~A} \mathrm{bcdns}$ & $219 \pm 64.5 \mathrm{~A}^{*}, \mathrm{bcdns}$ \\
\hline $\begin{array}{l}\text { Proliferative } \\
\mathrm{N}=30\end{array}$ & 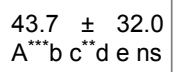 & $\begin{array}{l}37.5 \pm 28.3 \\
A^{* *} b c d e n s\end{array}$ & $132.4 \pm 37.6 \mathrm{~A}, \mathrm{~b}, \mathrm{c}, \mathrm{d}, \mathrm{e} \mathrm{ns}$ & $\begin{array}{l}47.3 \pm 8.5 \mathrm{~A}^{* * *} \mathrm{~b} \mathrm{c} \\
\text { de ns }\end{array}$ & $151.0 \pm 79.8$ A bc de ns & $215 \pm 56.3 A^{*}, b c d$ ens \\
\hline
\end{tabular}

Table 2: Liver functions and lipid profile in different groups of patients. Data are expressed as mean \pm SD, A: refers to frank group B: refers to Diabetic control group C: refers to Mild group, D: refers to Mod. group E: refers to Sever group. P value $>0.05$ Non-significant(ns), ${ }^{*}$ Significant at level $<0.01,{ }^{* *}$ highly Significant at level $<0.00,{ }^{* * *}$ very highly Significant $<0.000$, P value 0.01 to 0.05 Significant ${ }^{*}, \mathrm{P}$ value 0.0001 to 0.01 high significant $^{* *}$, P value 0.0001 to 0.001 extremely significant ${ }^{* * *}$

\begin{tabular}{|c|c|c|c|c|c|}
\hline \multirow[b]{2}{*}{ Normal range } & \multirow{2}{*}{$\begin{array}{l}\text { FBG (mg/dl) } \\
70-120\end{array}$} & \multicolumn{2}{|l|}{ HbA1C } & \multirow[b]{2}{*}{ VEGF (pg/ml) 30-1200 } & \multirow[b]{2}{*}{ Taurine $(\mathrm{mmol} / \mathrm{L})$ Up to 55} \\
\hline & & $\begin{array}{l}\text { NGSP \% } \\
4.5-6.5\end{array}$ & $\mathrm{IFCC}(\mathrm{mmol} / \mathrm{mol})$ & & \\
\hline Frank $\mathrm{N}=20$ & $88.9 \pm 3.67$ & $5.4 \% \pm 0.34$ & 35 & $199.5 \pm 37.5$ & $63.15 \pm 3.8$ \\
\hline Diabetic control $\mathrm{N}=10$ & $172 \pm 2.3 \mathrm{~A}^{\star \star * *}$ & $6.8 \% \pm 0.17 \mathrm{~A}$ & 48 & $94.11 \pm 8.5 \mathrm{~A}^{*}$ & $38.8 \pm 1.1 \mathrm{~A}^{* * *}$ \\
\hline Mild N=10 & $170.6 \pm 17.1 \mathrm{~A}^{\star \star *} \mathrm{~b} n \mathrm{~s}$ & $7.9 \% \pm 2.2 \mathrm{~A}^{* *}, \mathrm{~b} \mathrm{~ns}$ & 63 & $126.4 \pm 47 A^{*}, b n s$ & $34.7 \pm 0.7 \mathrm{~A}^{\star \star *}, \mathrm{~b}^{\star}$ \\
\hline Moderate $\mathrm{N}=10$ & $248.5 \pm 76.1 \mathrm{~A}^{* * *}, \mathrm{~b} \mathrm{c} n \mathrm{~s}$ & $10.03 \% \pm 1.9 \mathrm{~A}^{* * *} \mathrm{~b}^{* *} \mathrm{C}^{* *}$ & 86 & $144.9 \pm 37 A^{\star}, b, c n s$ & $29.6 \pm 2.2(\mathrm{~A}, \mathrm{~b}, \mathrm{c})^{*+* t}$ \\
\hline Sever $N=20$ & $238.6 \pm 98.5 A^{* * *}, b c d n s$ & $9.03 \% \pm 1.2 \mathrm{~A}^{* * *} b^{*} \mathrm{c} d \mathrm{~ns}$ & 75 & $135.3 \pm 59 A^{*}, b, c, d n s$ & $28.9 \pm 3.3(\mathrm{~A}, \mathrm{~b}, \mathrm{c})^{* * * *}, \mathrm{~d} \mathrm{~ns}$ \\
\hline Proliferative N-30 & $307.5 \pm 171.9 \mathrm{~A}^{* * *} \mathrm{~b}^{*} \mathrm{c}^{* *} \mathrm{de}$ & $11.4 \% \pm 2.5(\mathrm{~A} \mathrm{~b} \mathrm{c})^{* * *} \mathrm{~d}^{*} \mathrm{e}^{* * *}$ & 101 & $139.9 \pm 116 A^{\star *}, b, c, d, e n s$ & $23.5 \pm 2.3(\mathrm{~A}, \mathrm{bc}, \mathrm{d}, \mathrm{e})^{\star \star \star *}$ \\
\hline
\end{tabular}

Table 3: The fasting blood glucose, glaciated hemoglobin, vascular endothelial growth factor and serum taurine level in different groups of patients. Data are expressed as mean $\pm \mathrm{SD}$, A: refers to frank group B: refers to Diabetic control group C: refers to Mild group, D: refers to Mod. group E: refers to Sever group. P value $>0.05$ Non-significant (ns), ${ }^{*}$ Significant at level $<0.01,{ }^{* *}$ highly Significant at level $<0.00$, ${ }^{* * *}$ very highly Significant $<0.000$, P value 0.01 to 0.05 Significant $^{*}$, P value 0.0001 to 0.01 high significant ${ }^{* *}, \mathrm{P}$ value 0.0001 to 0.001 extremely significant $^{* * *}$.

Confirming all previous biochemical analysis and investigation, the ophthalmoscope examination was done for all patients with diabetes showed photos for the different groups Photo 1 (diabetic control) showed normal image. Photo 2 (mild non-proliferative) showed small area like a balloon swelling in retina tiny blood vessel, Photo 3 (moderate non-proliferative) showed some blood vessels that nourish the retina are blocked, Photo 3 (sever non-proliferative) more blood vessels are blocked and depriving several areas of retina with their blood supply, Photo 4 (proliferative) more blood vessels are abnormal and fragile they grow along the retina and along surface vitrous gel that fills inside the eye (Photo 5). 
Citation: Agouza IME, Saad AH, Mahfouz AA, Hamdy K (2017) Serum Taurine Level in Relation to Ophthalmoscopic Examination as Early Marker for Diabetic Retinopathy. Clin Med Biochem 3: 124. doi:10.4172/2471-2663.1000124

Page 5 of 8

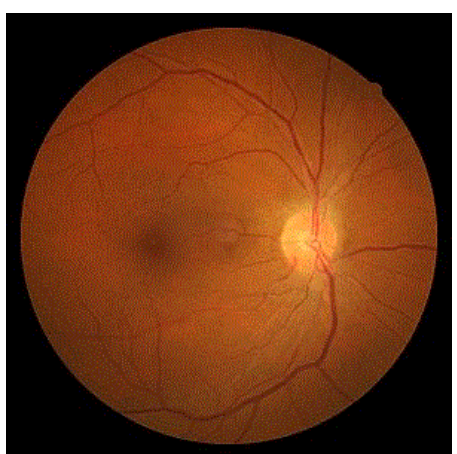

Photo 1: The ophthalmoscope examination diagnosed this picture as diabetic control patient which is normal image.

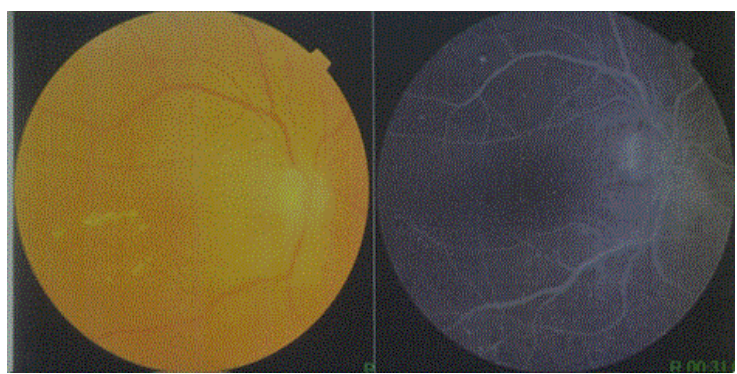

Photo 2: The ophthalmoscope examination diagnosed this picture as mild stage which is characterized by small area like balloons swelling in the retina tiny blood vessels.

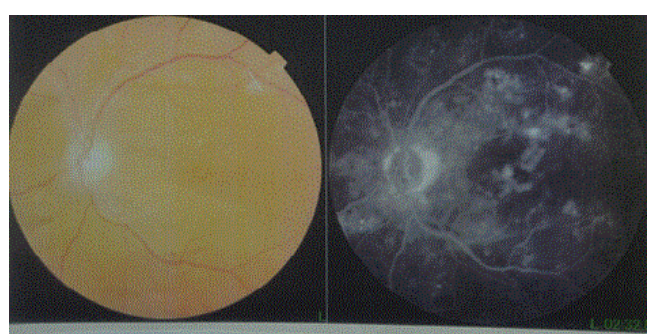

Photo 3: The ophthalmoscope examination diagnosed this picture as moderate stage which is characterized by some blood vessels that norish the retina is blocked.

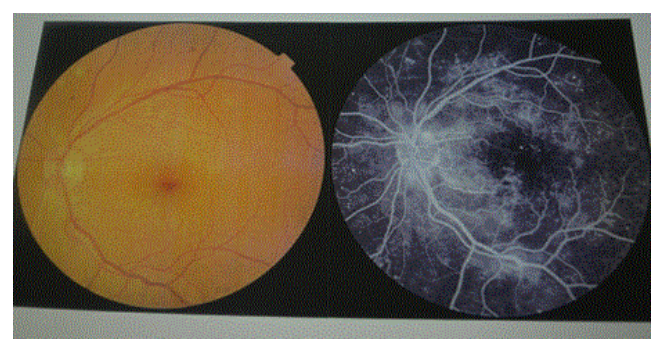

Photo 4: The ophthalmoscope examination diagnosed this picture as sever stage which is characterized by more blood vessels are blocked and depriving several areas of retina with their blood supply.

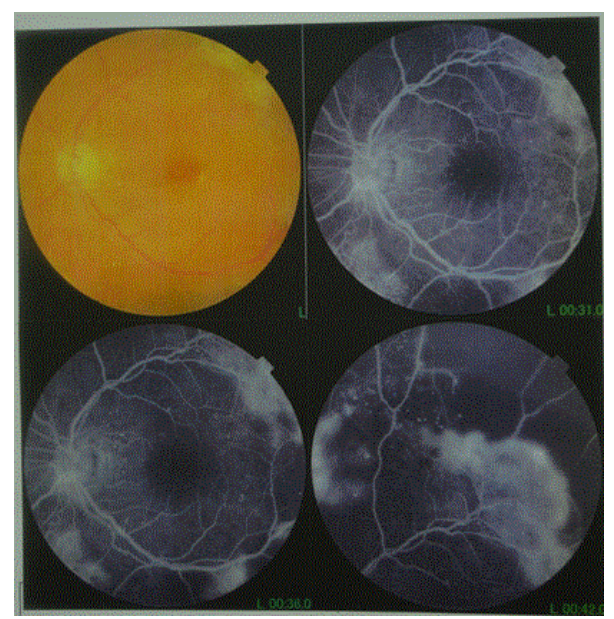

Photo 5: The ophthalmoscope examination diagnosed this picture as proliferative stage which is characterized by more blood vessels are abnormal and fragile they grow along the retina and surface vitreous gel that fills inside the eye.

\section{Discussion}

Diabetes disorder is a major public disease in Egypt with its complication especially ophthalmic complication as diabetic retinopathy. All the patients examined revealed no significant changes in lipid profile especially triglycerides and LDL. On contrary, HDL and cholesterol showed significant in all groups of diabetic patients with frank group. Significance changes recorded in liver functions especially in late stages of retinopathy. They were may be complicated with other complications of diabetes. It was found that abnormal liver function tests among diabetes patients can be indicator of associated nonalcoholic fatty liver disease [31].

There is evidence that expression of VEGF is reduced in patients with diabetes, and these diminution is associated with delayed healing in the wounds [32]. These is constant with our result whatever, this decrement is non-significant compared to frank control group as diabetic retina has decrease in blood supply and vascularity and wide normal range of VEGF (30-1200 pg/ml). Urea showed significant difference for all grades of retinopathy with frank group, all patients including the controlled diabetic group showed early appearance of 
albumin in urine in range between $1-30 \mathrm{mg} / \mathrm{dl}$ albuminurine, micro (more than 30 up to $300 \mathrm{mg} / \mathrm{dl}$ ) and macro albuminurea (more than $300 \mathrm{mg} / \mathrm{dl}$ ) which consider as early sign of diabetic nephropathy [33]. Fasting blood glucose and HbAlc showed an extreme increase in all patients compared to frank group $(\mathrm{p}<0.0001)$.

The most interesting finding in the present study is the marked decrement of serum taurine level $(38.8 \pm 1.1 \mathrm{mmol} / \mathrm{l})$. Among the controlled diabetic patients despite of normal ophthalmoscopic examination image and mild increment in FBG and HbAlc $(\mathrm{P}>0.05)$ comparing to that recorded in frank control group $(63.15 \pm 3.8$ $\mathrm{mmol} / \mathrm{l})$. Those patients coming to hospital for regular check-up and not complain from any diabetic complications. So, lowering in the serum taurine level in diabetic patients proceed the pathological changes in retina. Which can be considered as an early sign of diabetic retinopathy and the immediate induction of its treatment. These is consistence with other observation published in 2007 proved that plasma taurine in T2DM patients markedly lower than that recorded in healthy non-diabetic subject [34]. The taurine act as a hypoglycemic drug against both insulin depended and non- insulin depended diabetes mellitus $[35,36]$.

In the present study, such decrement in serum taurine level $(34.7 \pm$ $0.7,29.6 \pm 2.2,28.9 \pm 3.3 \mathrm{mmol} / \mathrm{l})$ was found parallel to the grading of non-proliferative retinopathy (mild, moderate and sever) respectively. The retina contains an extremely high amount of taurine and in some animal species the taurine levels in the retina are highest of any tissues $[37,38]$. It was found that taurine has several functions in the retina, which include the regulation of $\mathrm{Ca}$ transport, protection of the photoreceptor and regulation of signal transduction [39].

More ever, it was found that taurine suppressed high glucose induced defect of glutamate up take and degradation in cultured muller cell [40]. Also, it was supported that the taurine play important role in retinal ganglion cell neuro protection [41], while it was postulated that taurine possesses an anti-diabetic activity, reduced loss of body weight, and less electrophysiological changes of the diabetic retina [42]. In 2015, it was suggested that taurine has important role in the process of rhodopsin regeneration and in the protection of the rod outer segments against osmotic, mechanical and light induced damage [43].

The ordinary follow up for all chronic patients with diabetes is limited in measuring fasting blood glucose, post prandial blood glucose, glaciated hemoglobin and glucose in urine.

While numerous techniques have been propounded to diagnose the accuracy of DR including that; mean serum nitric oxide (NO), soluble interleukin-2 receptor (sIL2R), interleukin- 8 (IL-8), and tumornecrosis factor-alpha (TNF-alpha) levels have been shown to increase with the stage of DR with the highest levels being found in patients with PDR [44].

Serum levels of chemerin, a multifunctional peptide involved in lipid and glucose metabolism [45] has also been found to be elevated in patients with NPDR and PDR [46].

In NIDE hospital where our patients were collected, the diagnosis mainly depend on the biochemical analysis (FBG, HbAlc, post prandial glucose) and the imaging technique including COT and fluorescent technique.

More studies indicated the beneficial role of taurine on diabetic retinopathy. It is suggesting that taurine may normalize the retinal vascular function in diabetes [47]. Furthermore, while elevation of glutamate in retina is associated with the development of diabetic retinopathy, taurine prevented the elevation of retinal glutamate content and reduction of the proteins involved in glutamate uptake and degradation in STZ-treated diabetic rats [47].

The most series observation in the present study is that in the group of the proliferative retinopathy, taurine level recorded around $(23.5 \pm$ $2.3 \mathrm{mmol} / \mathrm{l})$ with an extremely significant decreased $(\mathrm{p}<0.0001)$ compared to controlled diabetic and frank groups. The taurine level is so close to the taurine level cut of value for cancer thus groups with diabetes disease may be at risk of developing cancer in different organs $[48,49]$. European study of individuals with metabolic syndrome showed the association between higher glucose levels and an increased risk of liver, gallbladder, respiratory, thyroid cancer and multiple myeloma in men, as well as pancreatic, bladder, endometrial, cervical and stomach cancer in women [7].

In the line with the present study It was suggested that, serum taurine concentrations were not affected by age and sex of patients [50].

In the present study, 50 persons with diabetes came to ophthalmology clinic with late stage retinopathy. Patients with diabetes mellitus usually visit ophthalmological clinic in late stage and they have irregular follow up [20]. The high frequency of the proliferative stage of diabetic retinopathy is a major health concern. Those are not sensitive enough to the severity and complications of the disease. So, any patients with type 1 or type 2 diabetes suffered from early blurring in vision must undergo a regular check up with ophthalmoscope examination and measure serum taurine level. The classification of ophthalmoscope will be enhanced by taurine level measurement. Taurine can play an important role in detecting any slight deterioration that may happen in the patient status.

A value of not below $50 \mathrm{mmol} / \mathrm{l}$ serum taurine is considered a safety margin for patients suffered from diabetes. Diabetic patients with lower values (less than $50 \mathrm{mmol} / \mathrm{l}$ ) are considered at risk for different complications of diabetes and supplementary taurine is recommended in an appropriate dose in addition to the prescribed therapy. Taurine supplementation is beneficial for type 1 and type 2 diabetes, including retinopthy, nephropathy, neuropathy and cardiopathy [22,51]. More ever, it was postulated that" taurine administration prevented the occurrence and development of diabetic nephropathy by decreasing blood glucose, improving lipid metabolism and glomerular basement membrane metabolism [52,53]. It was suggested that, the daily oral administration of MET (metformin) and taurine can effectively protect against diabetes-induced alteration in glucose and lipid metabolism, cholesterol, renal oxidative state and loose of renal function [54].

We advise new classification of diabetic retinopathy according to the serum taurine level beside check up by ophthalmoscope for all diabetic patients regularity as a pre early marker for any microvascular complications and it is prefers to sustain its level above $50 \mathrm{mmole} / \mathrm{l}$ as a safety margin. And when exhibited value between $40-50 \mathrm{mmol} / \mathrm{l}$ it is risky, and the diabetic patients become highly suspected for many complications. But, when it decreased below $40 \mathrm{mmol} / \mathrm{l}$ it mean that the patients suffered from other microvascular complications. Whatever, when its level exhibited value less than $30 \mathrm{mmol} / \mathrm{l}$, these mean that the diabetic patient become highly susceptible of developing cancer elsewhere in the body $[48,49]$. 


\section{Conclusion}

In conclusion, Regular check-up for all persons with diabetes mellitus by ophthalmoscope examination and measuring serum taurine level with its new classification could be used as early marker for microvascular complications especially diabetic retinopathy.

\section{References}

1. American Diabetes Association (ADA) (2014) Diagnosis and classification of diabetes mellitius. Diabetes Care 37: S81-S90.

2. King H, Aubert RE, Herman WH (1998) Global burden of diabetes, 1995-2025: prevalence, numerical estimates, and projections. Diabetes Care 21: 1414-1431.

3. Whiting DR, Guariguata L, Weil C (2011) Global estimated of prevalence of diabetes for 2011-2030. Diabetes Res Clin Pract 94: 311-321.

4. Hegazi R, El-Gamal M, Abdel-Hady N, Hamdy O (2015) Epidemiology of and Risk Factors for Type 2 Diabetes in Egypt 81: 814-820.

5. Forbes JM, Cooper ME (2013) Mechanisms of diabetic complications Physiological Reviews 93: 137-188.

6. Papa G, Degano C, Iurato MP, Licciardello C, Maiorana R, et al. (2013) Macrovascular complication phenotypes in type 2 diabetic patients. Cardiovascular Diabetology 12: 20-22.

7. Gordon-Dseagu VL, Shelton N, Mindell JS (2013) Epidemiological evidence of a relationship between type-1 diabetes mellitus and cancer: a review of the existing literature. International Journal of Cancer 132: 501-508.

8. Giovannucci E, Harlan DM, Archer MC, Richard MB, Susan MG, et al. (2010) Diabetes and cancer: a consensus report. Diabetes Care 33: 1674-1685.

9. Klein BE (2007) Overview of epidemiologic studies of diabetic retinopathy. Ophthalmic Epidemiology 14: 179-183.

10. Wilkinson CP, Ferris FL, Klein RE, Lee PP, Agardh CD, et al. (2003) Proposed international clinical diabetic retinopathy and diabetic macular edema disease severity scales. Ophthalmology 110: 1677-1682.

11. Adhi M, Brewer E, Waheed NK, Ducker JS (2013) Analysis of morphological features and vascular layers of choroid in diabetic retinopathy using spectral domain optical coherence tomography. JAMA Ophthalmology 131: 1267-1274.

12. Girach A, Lund-Andersen H (2008) Diabetic macular edema: A clinical overview. Int J Clin Pract 61: 88-97.

13. Drexler W, Fujimoto JG (2008) State-of-the-art retinal optical coherence tomography. Progress in Retinal and Eye Research 27: 45-88.

14. Leung DW, Cachianes G, Kuang WJ, Goeddel DV, Ferrara N (1989) Vascular Endothelial Growth Factor Is a Secreted Angiogenic Mitogen. Science 246: 1306-1309.

15. Claffey KP, Robinson GS (1996) Regulation of VEGF/VPF expression in tumor cells, consequence for tumor growth and metastasis. Cancer Metastasis Rev 15: 165-176.

16. Wirostko B, Wong TY, Simo R (2008) Vascular endothelial growth factor and diabetic complications. Progress in Retinal and Eye research 27: 608-621.

17. Witmer AN, Vrensen GF, Van NCJ, Schlingemann RO (2003) Vascular endothelial growth factor sand angiogenesis in eye disease. Prog Retin Eye Res 22: 1-29.

18. Adamise AP, Miller JW, Bernal MTD, Amico DJ, Folkman J, et al. (1994) Increased Vascular endothelial growth factor levels in the vitreous of eyes with proliferative diabetic retinopathy. Am J Ophthalmol 118: 445-450.

19. Yau JW, Rogers SL, Kawasaki R, Ecosse LL, Jonathan WK, et al. (2012) Global prevalence and major risk factors of diabetic retinopathy. Diabetes care 35: 556-564.

20. Moss SE, Klein R, Klein BE (1994) Ten-year incidence of visual loss in a diabetic population. Ophthalmology 101: 1061-1070.

21. Mohamed Q, Gillies MC, Wong TY (2007) Management of diabetic retinopathy a systematic review. JAMA 298: 902-916.
22. Ito T, Schaffer WS (2012) The potential usefulness of taurine on diabetes mellitus and its complication. Amino Acid May 42: 1529-1539.

23. Chorazy M, Kontay E, Marcinkiewicz J, Maslinki W (2002) Taurine chloramines modulate cytokine production by human peripheral blood momnonuclear cell. Amino Acid 23: 407-413.

24. Franconi F, Di Leo MA, Bennardini F, Ghirlanda G (2004) Is a taurine beneficial in reducing risk factors for diabetes mellitus? Neurochem Res 29: 143-150.

25. Sun Q, Wang B, Li Y, Sun F, et al. (2016) Taurine supplementation lower blood pressure and improves vascular function in pre hypertension. Hypertension Mars 67: 541-549.

26. Moloney MA, Casey RG, Fitzgerald P, et al. (2010) Two weeks taurine supplementation reverses endothelial dysfunction in young male type1 diabetes. Diab Vasc Dis Res 7: 300-310.

27. Kim T, Kim AK (2013) Taurine enhances anticancer activity of cisplatin in human cervical cancer cells. Adv Exp Med Biol 776: 189-198.

28. Marc RE, Cameron D (2001) A molecular phenotype atlas of the zebra fish retina. J Neurocytol 30: 593-654.

29. Lima L, Cubillos S (1998) Taurine might be acting as atrophic factor in the retina by modulating phosphorylation of cellular proteins. Neurosci Res 53: 337-384.

30. Segal P, Treister G, Yalon M, et al. (1983) The Prevalence of Diabetic Retinopathy: Effect of Sex, Age, Duration of Disease, and Mode of Therapy. Diabetes Care Mar 6: 149-151.

31. Han Ni, Soe HK, Htet A (2012) Determinates of abnormal liver functions test in diabetes patients in Mayanmar. International Journal of Diabetes Research 1: 36-41.

32. Jazwa A, Kucharzewska P, Leja J, Zagorska A, Sierpniowska A et al. (2010) Combined Vascular endothelial growth factor A-and fibroblast growth factor 4gene transfer improves wound healing in diabetic mice. Genet Vaccines Ther 8: 6 .

33. Levin A (2014) Stevens PE: Summary of KDIGO 2012 CKD Guideline: behind the scenes, need for guidance and a framework for moving forward. Kidney International 85: 49-61.

34. Merheb M, Daher RT, Nasrallah M, Sabra R, Ziyadeh FN, et al. (2007) Taurine intestinal absorption and renal excretion test in diabetic patients: a pilot study. Diabetes Care 30: 2652-2654.

35. Gavrovskaya LK, Ryzhova OV, Safonova AF, Matveev AK, Sapronov NS (2008) Protective effect of taurine on rats with experimental insulindependent diabetes mellitus. Bull Exp Biol Med 146: 226-228.

36. Schaffer SW, Azuma J, Mozaffari M (2009) Role of antioxidant activity of taurine in diabetes. Can J Physiol Pharmacol. 87: 91-99.

37. Yates RA, Keen P (1975) The effects of optic stalk section on the amino acid content of rat retina. Brain Res 99: 166-169.

38. Lund Karisen R, Fonnum F (1976) The toxic effect of sodium glutamate on rat retina: changes in putative transmitters and their corresponding enzymes. J Neurochem 27: 1437- 1441.

39. Lombardini JB (1991) Taurine: retinal function. Brain Research Reviews 16: 151-169.

40. Zeng K, Xu H, Chen K, Zhu J, Zhou Y, et al. (2010) Effects of taurine on glutamate uptake and degradation in Müller cells under diabetic conditions via antioxidant mechanism. Mol Cell Neurosci 45: 192-199.

41. Gaucher D, Arnault E, Husson Z, Froger N (2012) Taurine deficiency damages retinal neurons, cone photoreceptors and retinal ganglion cells. Amino Acid 43: 1979-1993.

42. Tung S, Chiang H, Yeh M (2014) Investigation of the Protective Effects of Taurine against Alloxan-Induced Diabetic Retinal Changes via Electroretinogram and Retinal Histology with New Zealand White Rabbits. International Journal of Endocrinology pp: 1-7.

43. Ma N, Wang S, Okita S, Kato T, Huang S, et al. (2015) Contribution of taurine signatures in the detached cat retina. Adv Exp Med Biol 803: 439-447.

44. Doganay S, Evereklioglu C, Er H, Turkoz Y, Sevinc A, et al. (2002) Comparison of serum NO, TNF-alpha, IL-1beta, sIL-2R, IL-6 and IL-8 
Citation: Agouza IME, Saad AH, Mahfouz AA, Hamdy K (2017) Serum Taurine Level in Relation to Ophthalmoscopic Examination as Early Marker for Diabetic Retinopathy. Clin Med Biochem 3: 124. doi:10.4172/2471-2663.1000124

Page 8 of 8

levels with grades of retinopathy in patients with diabetes mellitus. Eye 16: $163-170$.

45. Fatima S, Butt Z, Bader N, Pathan A, Hussain S, et al. (2015) Role of multifunctional chemerin in obesity and preclinical diabetes. Obes Res Clin Prac 9: 5-8.

46. Du J, Li R, Xu L, Ma R, Liu J, et al. (2016) Increased serum chemerin levels in diabetic retinopathy of type 2 diabetic patients. Curr Eye Res 41: 114-120.

47. Zeng K, Xu H, Mi M, Zhang Q, Zhang Y, et al. (2009) Dietary taurine supplementation prevents glial alterations in retina of diabetic rats. Neurochem Res 34: 244-254.

48. Agouza I, Essa SS, EL-Houssini MM, EL-Nashar DE, Abdl-Hameed OM (2011) Taurine; A noval tumor marker for enhanced detection of breast cancer among female patients. Angiogenesis 14: 321-330.

49. Agouza IM, Nashar DE (2011) Serum Taurine as a Marker of Endometrial Cancer. The Open Women's Health Journal 5: 1-6.

50. Heinze CR, Larsen JA, Kass PH, Fascetti AJ (2009) Plasma amino acid and whole blood taurine concentrations in cats eating commercially prepared diets. Am J Vet Res 70: 1374-1382.
51. Li C, Cao L, Zeng Q, Liu X, Zhang Y, et al. (2005) Taurine may prevent diabetic rats from developing cardiomyopathy also by downregulating angiotensin II type 2 receptor expression. Cardiovasc Drugs Ther 19: 105-112.

52. Lin S, Yang J, Wu G (2010) Preventive effect of taurine on experimental type II diabetic nephropathy. Journal of Biomedical Science 17: S46.

53. Patel SN, Parikh M, Lau-Cam CA (2015) Impact of light ethanol intake and of taurine, separately and together, on pathways of glucose metabolism in the kidney of diabetic rats. Adv Exp Med Biol 803: 279-303.

54. Pandya KG, Budhram R, Clark GJ, Lau-Cam CA (2015) Taurine can enhance the protective actions of metformin against diabetes-induced alterations adversely affecting renal function. Adv Exp Med Biol 803: 227-250. 